CASE REPORT

\title{
Disseminated Mycobacterium tuberculosis infection due to interferon $\gamma$ deficiency. Response to replacement therapy
}

\author{
Suranjith Luke Seneviratne, Rainer Doffinger, John Macfarlane, L Ceron-Gutierrez, M R Amel \\ Kashipaz, A Robbins, T Patel, P T Powell, D S Kumararatne, Richard J Powell
}

Thorax 2007;62:97-99. doi: 10.1136/thx.2005.051649

The case of a previously healthy HIV seronegative woman with disseminated Mycobacterium tuberculosis infection and markedly reduced interferon $\gamma$ production is reported here. Complete healing of her disseminated lesions was seen only after addition of subcutaneous interferon $\gamma$ to her tuberculosis treatment.

an nfections with intracellular bacteria such as mycobacteria are an important cause of human morbidity and mortality worldwide. Immunological protection against such organisms depends heavily on cell-mediated immunity, with the major effector being the interferon (IFN) $\gamma$ activated macrophage. ${ }^{1}$ The importance of IFN $\gamma$ pathways in host defence against intracellular bacteria was clarified by experimental studies on knockout mice. More recently, the identification and characterisation of humans with mutations in IFN $\gamma$ receptor proteins, interleukin (IL) 12 receptor $\beta 1$ or IL12 p40 has confirmed the importance of these pathways in human-host defence. Defects in the IFN $\gamma / \mathrm{IL} 12$ axis are well known to predispose individuals to infection with non-tuberculous mycobacteria or Salmonella species. ${ }^{2}$

To date, IFN $\gamma$ deficiency in humans has not been described, despite the identification of numerous IFN $\gamma$ receptor mutations in humans. The IFN $\gamma$ mouse-knockout model indicated that IFN $\gamma$ is not required for normal growth and development. However, these mice do not develop protective immunity after experimental infection with Mycobacterium bovis, Bacillus calmette guerin or $M$ tuberculosis Erdman strain. ${ }^{3}{ }^{4}$ Further, IFN $\gamma$ knockout mice experimentally infected with certain $M$ avium strains develop higher tissue levels of bacteria than wild-type mice and they do not develop protective immunity to some attenuated strains of Salmonella typhimurium. ${ }^{5}$ We report on a previously healthy HIV seronegative woman with disseminated $M$ tuberculosis infection due to a defect in IFN $\gamma$ production.

\section{CASE REPORT}

A 56-year-old white Caucasian woman presented with fever and right-sided chest pain, and was found to have a right pleural effusion confirmed on chest radiography (fig lA). $M$ tuberculosis (sensitive to standard and second-line tuberculosis drugs) was isolated from pleural biopsy material and standard quadruple tuberculosis treatment was started. Four months later, while taking standard tuberculosis treatment with documented compliance, she developed lower back pain and several discharging sinuses in her left forearm and palm (fig 1B). At this juncture there was minimal improvement in her right pleural fluid collection. A computed tomography scan of the abdomen showed a non-functioning left kidney with cystic changes (fig $\mathrm{lC}$ ), a magnetic resonance imaging vertebral scan showed vertebral body collapse with loss of intervertebral disc height (fig lD), and a magnetic resonance imaging hand/ forearm scan showed hyperdense material in the soft tissues of the hand (fig 1E). A left nephrectomy was undertaken and macroscopically the appearance was of renal tuberculosis. Microscopically, poorly formed granuloma with several acid fast bacilli were noted. Smears taken at this time were acid fast bacilli positive and $M$ tuberculosis (sensitive to the drugs the patient was taking at the time) was cultured. $M$ tuberculosis was also cultured from pleural fluid and from an early morning urine specimen. There was a strong family history of tuberculosis. Her father had died of tuberculosis at age 40 years despite treatment, her paternal uncle had tuberculosis and her paternal grandmother had died of tuberculosis at age 37 years. She was HIV negative and basic immunological tests showed: normal immunoglobulins, specific antibodies and lymphocyte subsets, with marginally reduced lymphocyte proliferation to OKT3. Cytokine quantification after whole blood stimulation showed markedly reduced IFN $\gamma$ production (both before treatment and after clinical resolution; fig 2). IFN $\gamma$ and IL12 receptor functions and $\mathrm{TNF} \alpha$ and IL12 levels were normal (fig 2), with no anti-IFN $\gamma$ antibodies detected (data not shown $)^{6}$. As her clinical condition was deteriorating despite administration of standard tuberculosis chemotherapy for 8 months with good compliance for a fully sensitive organism, subcutaneous IFN $\gamma$ three times a week $(50 \mu \mathrm{g}$ for 2 weeks, $75 \mu \mathrm{g}$ for 16 weeks followed by $50 \mu \mathrm{g}$ for 32 weeks) was added to her tuberculosis treatment. The addition of IFN $\gamma$ produced rapid improvement in her progressively worsening condition. IFN $\gamma$ and tuberculosis treatments were continued for 12 months, followed by tuberculosis drugs alone for a further 3 months. No major adverse effects of IFN $\gamma$ treatment were seen. There was complete healing (both clinical and radiological) of kidney, skin and bone lesions, and the pleural shadowing was largely resolved. In addition, the patient's weight increased by $5 \mathrm{~kg}$, inflammatory markers which had previously been markedly raised (C reactive protein $>100$, erythrocyte sedimentation rate $>100$ ) returned to normal, and she was able to resume her job that she had given up at the time her disease was becoming progressively worse. At follow-up, 9 months after stopping tuberculosis treatment, she remains well.

\section{DISCUSSION}

Our patient, a previously healthy HIV seronegative woman with disseminated $M$ tuberculosis infection, was found to have markedly reduced IFN $\gamma$ production. The addition of subcutaneous IFN $\gamma$ to her tuberculosis treatment led to complete healing of the disseminated lesions.

The importance of IFN $\gamma$ pathways in host defence has been demonstrated in mice with targeted disruptions of the IFN $\gamma$, IFN $\gamma \mathrm{R} 1$ or IFN $\gamma \mathrm{R} 2$ genes. Although similar problems with immunity to mycobacteria are seen in individuals with defects in IFN $\gamma$ receptors, to our knowledge, $M$ tuberculosis due to IFN $\gamma$ deficiency has not been reported previously.

Abbreviation: IFN, interferon 

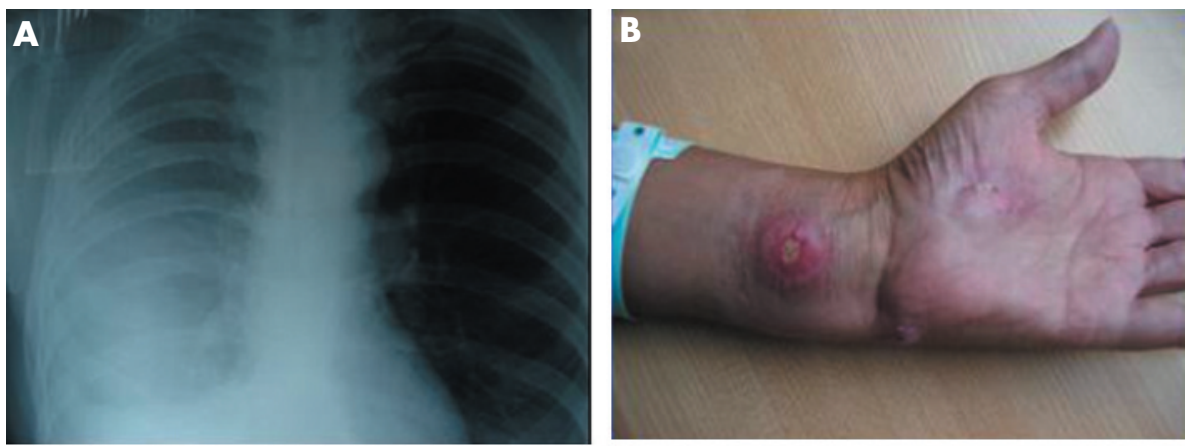

Figure 1 (A) Chest radiography showing right pleural effusion. (B) Forearm and palm of the patient with sinuses. (C) A computed tomography scan of the abdomen showing a non-functioning left kidney. (D) A magnetic resonance imaging vertebral scan showing vertebral body collapse with loss of intervertebral disc height. (E) Magnetic resonance imaging hand/forearm scan showing hyperdense material in the soft tissues of the hand.
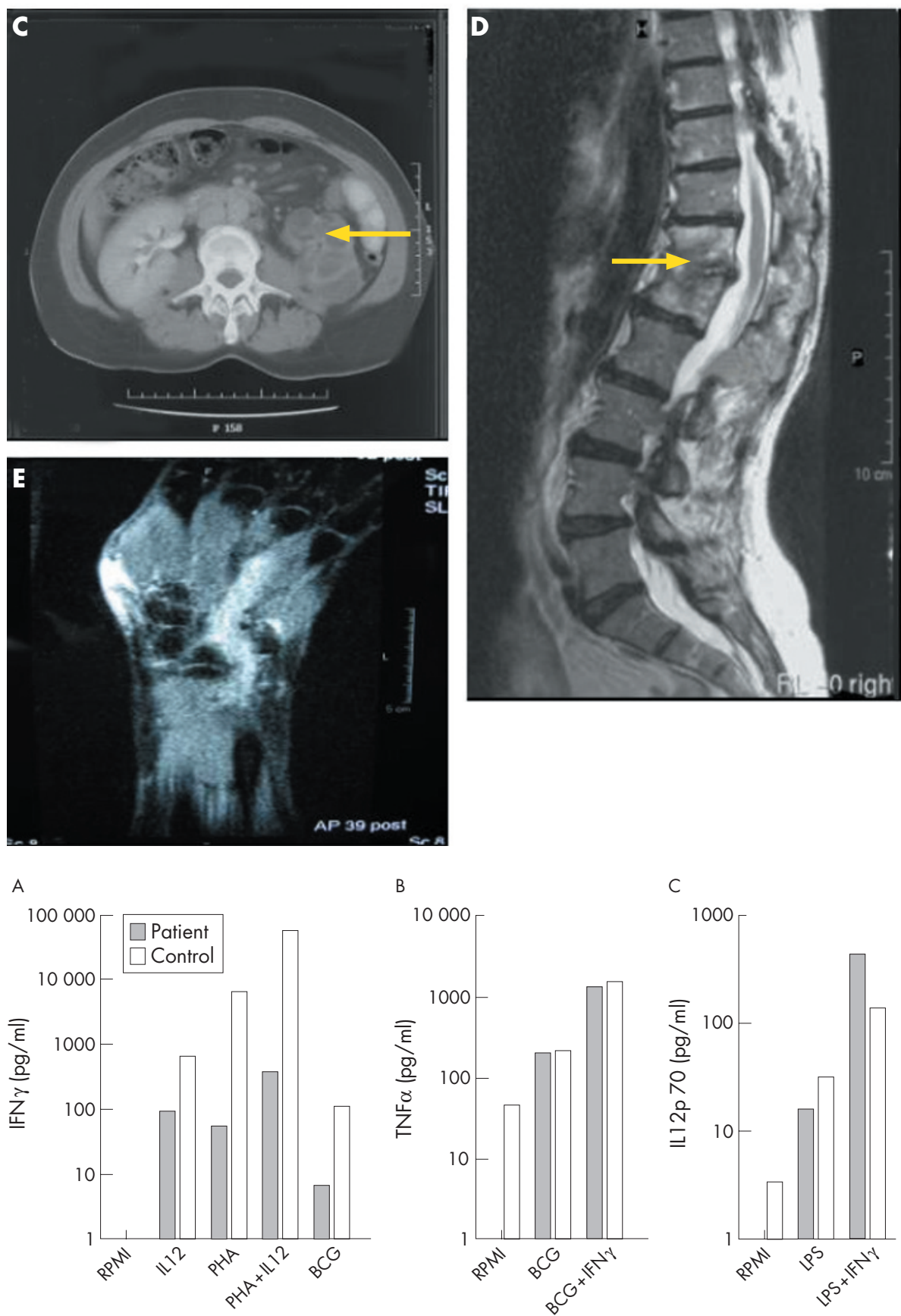

Figure 2 Interferon (IFN) $\gamma(\mathrm{A})$, tumour necrosis factor (TNF) $\alpha(B)$ and interleukin (IL) 12 (C) production after whole blood stimulation in vitro. Whole blood was diluted 1:5 with Rosewell Park Memorial Institute medium (RPMI) into 96-well F plates (Costar) and stimulated with IL12 $(20 \mathrm{ng} / \mathrm{ml}$, R\&D Systems, Abingdon, UK)

phytohaemagglutinin (PHA) $(10 \mu \mathrm{g} / \mathrm{ml}$, Sigma, Dorset, UK), Bacillus calmette guerin (BCG) $\left(1 \times 10^{\circ} \%\right.$ well, Statens Institute Copenhagen, Denmark) and lipopolysaccharide (LPS) $(1 \mu \mathrm{g} / \mathrm{ml}$, List Biochemicals Epson, UK). Supernatants were taken at $12 \mathrm{~h}$ (TNF $\alpha$, IL 12) and $48 \mathrm{~h}$ (IFN $\gamma$ ). Cytokines were measured using standard ELISA according to the manufacturer's recommendations (IFN $\gamma$, TNF $\alpha$ : CLB; IL12: R\&D Systems). One representative out of two experiments is shown. In-house reference ranges (mean (SD) $\mathrm{pg} / \mathrm{ml}$ ) for IFN $\gamma$ production are: medium, 5.8 (16); IL12, 24 (62); PHA, 6628 (4209); PHA+IL12, 26166 (14 657); BCG, 151 (225). 
Hence, screening the IFN $\gamma /$ IL12 axis of patients without HIV with disseminated tuberculosis or progressive tuberculosis disease despite having fully sensitive organisms and good compliance should be considered, as it may allow initiation of appropriate life-saving treatment.

\section{Authors' affiliations}

Suranjith Luke Seneviratne*, M R Amel Kashipaz, A Robbins, T Patel,

P T Powell, R J Powell, Clinical Immunology Unit, Queens Medical Centre, Nottingham, UK

Rainer Doffinger*, D S Kumararatne, Department of Immunology, Addenbrookes Hospital, Cambridge, UK

L Ceron-Gutierrez, Department of Clinical Biochemistry and Immunology, Addenbrookes Hospital, Cambridge, UK

John Macfarlane, Respiratory Medicine Department, Nottingham City Hospital, Nottingham, UK

*These authors contributed equally to this paper.

Competing interests: None declared.

Informed consent has been obtained from the patient for publication of her details in this paper.
Correspondence to: Dr Suranjith Luke Seneviratne, Department of Clinical Immunology, Manchester Royal Infirmary Manchester M13 9WL, UK; suran200@yahoo.co.uk

Received 16 August 2005

Accepted 12 December 2005

\section{REFERENCES}

1 Lammas DA, Casanova JL, Kumararatne DS. Clinical consequences of defects in the IL-12 dependent interferon-gamma (IFN- $\gamma$ ) pathway. Clin Exp Immunol 2000;121:417-25

2 Casanova JL, Abel L. Genetic dissection of immunity to mycobacteria: the human model. Annu Rev Immunol 2002;20:581-620.

3 Jouanguy $E$, Doffinger R, Dupuis $S$, et al. IL- 12 and IFN- $\gamma$ in host defence against mycobacteria and salmonella in mice and men. Curr Opin Immunol 1999;11:346-51

4 Cooper AM, Dalton DK, Stewart TA, et al. Disseminated tuberculosis in interferon- $\gamma$ gene disrupted mice. J Exp Med 1993;178:2243-7.

5 Dorman SE, Holland SM. Interferon- $\gamma$ and IL-12 pathway defects and human disease. Cytokine Growth Factor Rev 2000;1 1:321-33.

6 Doffinger R, Helbert MR, Barcenas-Morales G, et al. Autoantibodies to interferon- $\gamma$ in a patient with selective susceptibility to mycobacterial infection and organ-specific autoimmunity. Clin Infect Dis 2004;38:e10-4. 